\title{
Method Development for Quantification of Donor-Acceptor Complexes of Alverine Citrate and Tapentadol by Visible Spectrophotometry
}

\author{
Vijayalakshmi Rajendran*, Naga Sri Ramya Yerrapothini, Sasi Kiran Guntamukkala, Keziya Sugandha, Dhanaraju \\ Magharla Dasaratha \\ GIET School of Pharmacy, Rajahmundry, Andhra Pradesh, India.
}

\begin{tabular}{|c|c|}
\hline ARTICLE INFO & ABSTRACT \\
\hline Article history: & \multirow{6}{*}{$\begin{array}{l}\text { In this present work two colorimetric methods were developed based on donor-acceptor complexes of alverine } \\
\text { citrate (ALV) and tapentadol (TAP) with cobalt thiocyanate. These methods were developed on Perkin Elmer } \\
\text { LAMBDA } 25 \text { UV-VIS spectrophotometer with } 1 \mathrm{~cm} \text { quartz cells. The colored species formed are the } \\
\text { coordination complexes of the drugs (electron donor) and the central metal atom of cobalt thiocyanate (electron } \\
\text { acceptor) which is extractable into nitrobenzene from aqueous solution. The reaction conditions were optimized } \\
\text { and validated to achieve maximum colour intensity. The colored complexes show maximum absorbance } \\
\text { measured at } 625 \mathrm{~nm} \text { for both ALV and TAP. The absorbances were found to increase linearly with an increase in } \\
\text { concentration which was corroborated by the calculated regression coefficients }(0.9998-0.9999) \text {. Linearity was } \\
\text { obeyed in the range of } 100-600 \mu \mathrm{g} / \mathrm{ml} \text { for both ALV and TAP, respectively. The molar absorptivity, sandell's } \\
\text { sensitivity, LOD, LOQ and other validation parameters have been evaluated extensively as per ICH guidelines } \\
\text { and all the parameters were found within the acceptance criteria for both methods. The proposed methods were } \\
\text { proven to be more accurate, simple, precise and rapid by statistical validation of recovery studies and could be } \\
\text { suitable for regular analysis. }\end{array}$} \\
\hline Received on: 04/05/2015 & \\
\hline Revised on: 02/06/2015 & \\
\hline Accepted on: 18/06/2015 & \\
\hline Available online: $28 / 08 / 2015$ & \\
\hline $\begin{array}{l}\text { Key words: } \\
\text { Alverine citrate, cobalt } \\
\text { thiocyanate, nitrobenzene, } \\
\text { tapentadol. }\end{array}$ & \\
\hline
\end{tabular}

\section{INTRODUCTION}

\begin{abstract}
Alverine citrate (British Pharmacopoeia, 2008) chemically is N-Ethyl-N-(3-phenyl propyl)-benzene propanamine (Fig. 1) also called as spasmaverine used as an antispasmodic by directly acting on the muscle in the gut to relax. Tapentadol (Singh et al., 2013), chemically 3-[(1R, 2R)-3(dimethylamino)-1-ethyl-2-methylpropyl]phenol hydrochloride (Fig. 2) is a centrally acting opioid analgesic. Literature is enriched with several techniques like HPLC and spectrophotometry for the determination of TAP (Asha et al., 2012; Babu and Madhu, 2012; Deepti and Pawan, 2013; Indira et al., 2013; Krishanmurthy et al., 2014; Neol et al., 2009; Omkar and Priti, 2012; Rizwana et al., 2014; Suresh et at., 2013) and ALV( Vijayalakshmi et al., 2014; Ghosh et al., 2010; Rahul et al., 2011; Kumar et al., 2013). The reported methods suffer from
\end{abstract}

\footnotetext{
* Corresponding Author

Email: vijayalakshmigsp@gmail.com
}

one or more disadvantages such as narrow linear response, lack of sensitivity and selectivity and usage of expensive reagents. The need for sensitive, cost effective and reliable spectrophotometric methods for the selected drugs is thus obviously recognized. Spectrophotometry is by far the instrumental technique of choice in the laboratories of under developed and developing nations for the quantification of drugs owing mainly to its simplicity, high sensitivity and selectivity and often demanding low cost equipment.

The tertiary amino group present in both drugs has been exploited for quantification of the drugs by the chemical reaction with cobalt thiocyanate to give the coordination complex. The coordination complexes were soluble in organic solvent and could be separated and quantified. The present work was aimed to explore the significance of donor-acceptor complexes with cobalt thiocyanate which was not reported earlier for the quantitative analysis of ALV/TAP and to validate the methods accordingly with the ICH guidelines. 


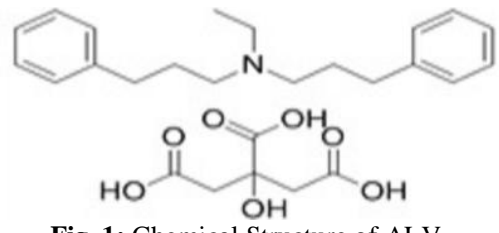

Fig. 1: Chemical Structure of ALV.

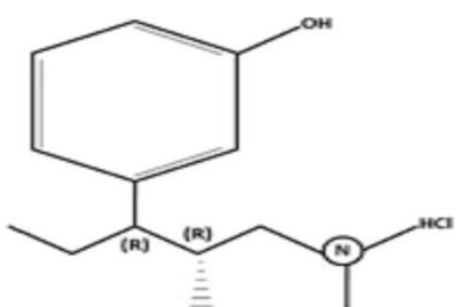

Fig. 2: Chemical Structure of TAP.

\section{EXPERIMENTAL}

\section{Instruments}

Double-beam Perkin Elmer (LAMBDA 25) UV-Vis spectrophotometer with $1 \mathrm{~cm}$ matched quartz cells was used for spectral measurements. Samples were weighed using Sartorius electronic balance.

\section{Chemicals}

Pharmaceutical grade ALV and TAP was graciously donated by Aurobindo Pharma Ltd, Hyderabad. Cobalt thiocyanate, nitrobenzene and hydrochloric acid of AR grade were used for the experimental work. Double distilled water was used in the preparation of solutions. All the preparations were prepared afresh daily.

Preparation of cobalt thiocyanate (0.25M)

Accurately $7.25 \mathrm{~g}$ of cobalt nitrate and $3.8 \mathrm{~g}$ of ammonium thiocyanate was weighed and taken together in $100 \mathrm{ml}$ volumetric flask, dissolved and diluted to the final volume with distilled water.

\section{Preparation of $0.2 \mathrm{M}$ hydrochloric acid}

Accurately $1.7 \mathrm{ml}$ of concentrated hydrochloric acid was diluted to $100 \mathrm{ml}$ with distilled water to get $0.2 \mathrm{M} \mathrm{HCl}$ solution.

Preparation of standard stock solution for estimation of $A L V$

Accurately $25 \mathrm{mg}$ of ALV was weighed and transferred to a $25 \mathrm{ml}$ volumetric flask, dissolved and diluted to final volume with water. The resulting solution has a concentration of $1 \mathrm{mg} / \mathrm{ml}$.

Preparation of standard stock solution for estimation of TAP

Accurately $25 \mathrm{mg}$ of TAP was weighed and transferred to a $25 \mathrm{ml}$ volumetric flask, dissolved and diluted to final volume with water. The resulting solution has a concentration of $1 \mathrm{mg} / \mathrm{ml}$.

\section{Procedure for calibration plot of $A L V$}

Into a series of $50 \mathrm{ml}$ separating funnels appropriate volume of $0.5-3.0 \mathrm{ml}(1 \mathrm{ml}=1 \mathrm{mg} / \mathrm{ml})$ of $\mathrm{ALV}$ was pipetted out and
$0.5 \mathrm{ml}$ of $\mathrm{HCl}(0.2 \mathrm{M}), 0.3 \mathrm{ml}$ of $(0.25 \mathrm{M})$ cobalt thiocyanate reagent was added, mixed well followed with $5 \mathrm{ml}$ of nitrobenzene and mixed well, allow to separate the two layers. The absorbance of the greenish blue coloured organic layer was measured at $625 \mathrm{~nm}$ against reagent the blank. The amount of ALV present in the sample solution was computed from its calibration curve.

Procedure for calibration plot of TAP

Into a series of $50 \mathrm{ml}$ separating funnels appropriate volume of $0.5-3.0 \mathrm{ml}(1 \mathrm{ml}=1 \mathrm{mg} / \mathrm{ml})$ of TAP was pipetted out and $1 \mathrm{ml}$ of $\mathrm{HCl}(0.2 \mathrm{M}), 1 \mathrm{ml}$ of $(0.25 \mathrm{M})$ cobalt thiocyanate reagent was added and mixed; followed by $5 \mathrm{ml}$ nitrobenzene and shaken thoroughly, allowed to separate the two layers.

The absorbance of the greenish blue coloured organic layer was measured at $625 \mathrm{~nm}$ against reagent blank prepared similarly in each case. The amount of TAP present in the sample solution was computed from its calibration curve.

\section{Assay procedure for $A L V$}

Twenty tablets of commercial samples (Spasverin $60 \mathrm{mg}$ ) of ALV were accurately weighed and powdered. Tablet powder equivalent to $25 \mathrm{mg}$ of ALV was weighed and dissolved in $25 \mathrm{ml}$ water, filtered and the procedure was carried out as mentioned above in section 2.3.1.

\section{Assay procedure for TAP}

Twenty tablets of commercial samples of TAP (Tapenta $100 \mathrm{mg}$ ) were accurately weighed and powdered. Tablet powder equivalent to $25 \mathrm{mg}$ was weighed and dissolved in $25 \mathrm{ml}$ water, filtered and the procedure was carried out as mentioned above in section 2.3.2.

\section{RESULTS AND DISCUSSION}

\section{Optimization of the Method}

The method was optimized by selecting the proper chromogen, concentration of the reagent, order of addition, selection of the wavelength, linearity and stability of the coloured product.

\section{Selection of the chromogenic reagent}

Several chromogenic reagents like cobalt thiocyanate, citric acid/acetic anhydride, N-bromosuccinimide has been studied and cobalt thiocyanate has been proved to be a valuable chromogenic reagent for the detection and determination of ALV/TAP based on the sensitivity of the method.

The colored product was formed by the coordination complex of the drug (electron donor) and the central metal atom of cobalt thiocyanate (electron acceptor) which was extractable into nitrobenzene from aqueous solution, hence could be separated and quantified. 


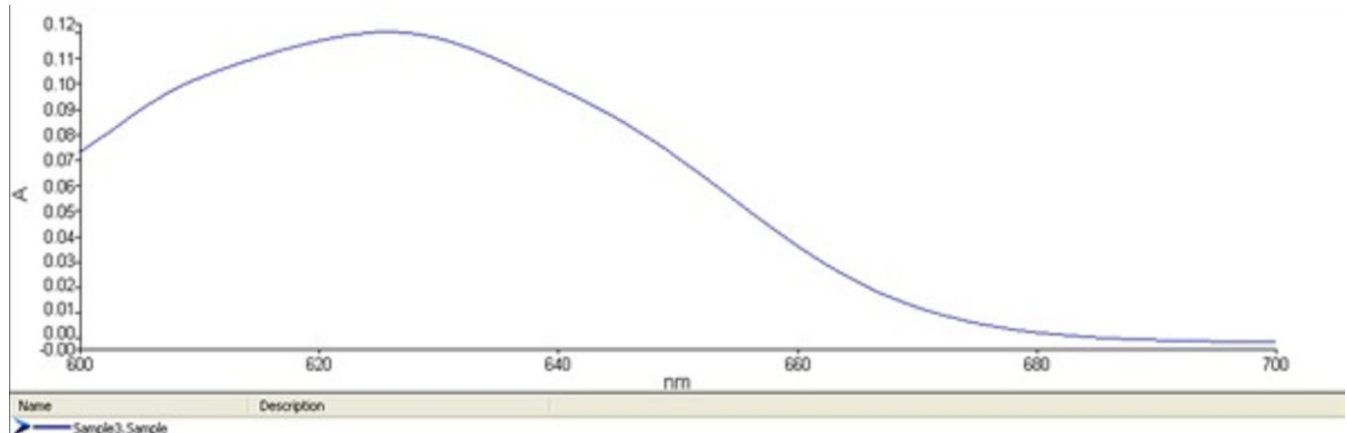

Fig. 3: Absorption spectrum of ALV by proposed method.

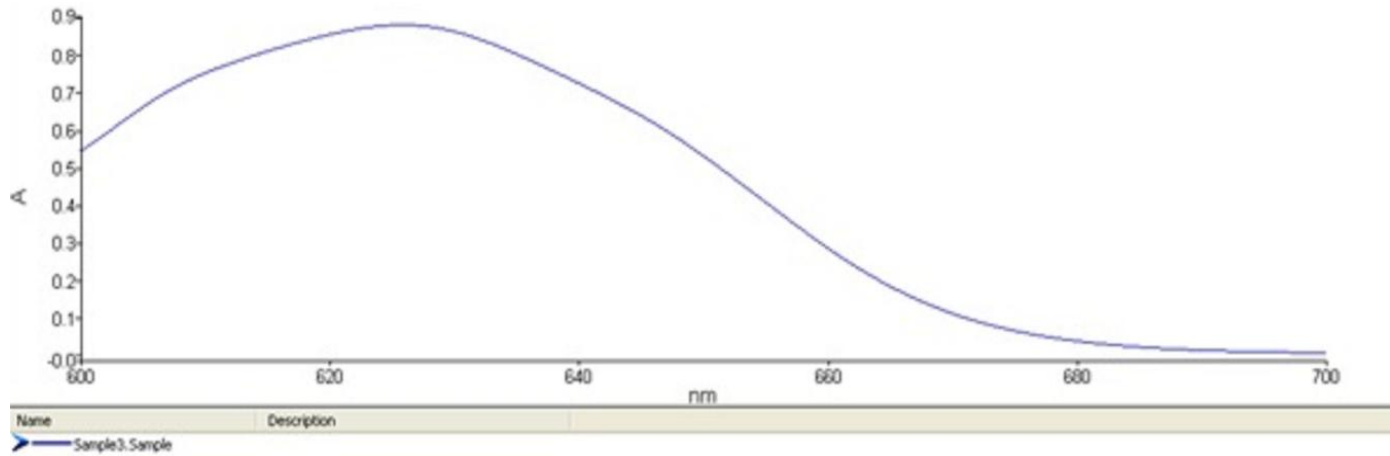

Fig. 4: Absorption spectrum of TAP by proposed method.

\section{Effect of cobalt thiocyanate concentration}

It was studied by treating the fixed volume of ALV/TAP and $\mathrm{HCl}$ concentration and in-turn varying the volume of cobalt thiocyanate from 0.1-2.0 ml. The results for both methods were depicted in Table 1.

Table 1: Order of addition/concentration of reagents for the proposed methods. $0.5 \mathrm{ml}(0.2 \mathrm{M}) \mathrm{HCl}+0.3 \mathrm{ml}(0.25 \mathrm{M})$ Cobalt thiocyanate $+\mathrm{ALV}+$ nitrobenzene $1 \mathrm{ml}(0.2 \mathrm{M}) \mathrm{HCl}+\mathrm{TAP}+1 \mathrm{ml}(0.25 \mathrm{M})$ Cobalt thiocyanate + nitrobenzene

\section{Effect of time/temperature on reaction}

The effect of time and temperature on the formation of the coloured complex was studied for the both methods. The complex formation was complete in 5-7 min time interval at room temperature for both the drugs. Fig. 3 and 4 represents the absorption spectrum of ALV and TAP, respectively.

\section{Method validation}

All the methods were validated for accuracy, precision, linearity, LOD, LOQ, ruggedness and robustness and the results were found to be satisfactory.

\section{Linearity and range}

At the described experimental conditions for ALV/TAP standard calibration curves were constructed by plotting an increase in absorbance with concentration (Fig 6 and 7). A linear correlation was found between absorbance and concentration of ALV/TAP as shown in Table 2 and all the parameters regarding linearity were given in Table 3.

Table 2: Linearity data of absorbance against concentration.

\begin{tabular}{cccc}
\hline \multicolumn{2}{c}{ ALV } & \multicolumn{2}{c}{ TAP } \\
\hline Conc $(\boldsymbol{\mu g} / \mathbf{m l})$ & Absorbance & Conc $(\boldsymbol{\mu g} / \mathbf{m l})$ & Absorbance \\
\hline 100 & 0.18 & 100 & 0.30 \\
200 & 0.35 & 200 & 0.58 \\
300 & 0.52 & 300 & 0.85 \\
400 & 0.68 & 400 & 1.13 \\
500 & 0.85 & 500 & 1.42 \\
600 & 1.02 & 600 & 1.71 \\
\hline
\end{tabular}

Table 3: Optical and regression parameters.

\begin{tabular}{lll}
\hline \multicolumn{1}{c}{ Parameters } & ALV & TAP \\
\hline$\lambda$ max, nm & 625 & \\
Beer's law range $(\mu \mathrm{g} / \mathrm{ml})$ & $100-600$ & \\
Molar absorptivity $\left(\mathrm{L} \cdot \mathrm{mole}^{-1} . \mathrm{cm}^{-1}\right)$ & $\begin{array}{l}1.7 \times 10^{5} \\
4 \times 10^{5}\end{array}$ & $\begin{array}{l}2.8 \times 10^{5} \\
4 \times 10^{5}\end{array}$ \\
$\begin{array}{l}\text { Sandell's sensitivity }\left(\mu \mathrm{g} / \mathrm{cm}^{2}\right) / 0.001 \\
\text { unit) }\end{array}$ & & \\
$\mathrm{LOD}, \mu \mathrm{g} / \mathrm{ml}$ & 10.31 & 9.65 \\
$\mathrm{LOQ}, \mu \mathrm{g} / \mathrm{ml}$ & 31.24 & 29.27 \\
Slope $(\mathrm{m})$ & 0.001689 & 0.002829 \\
Intercept $(\mathrm{b})$ & 0.0075 & 0.007143 \\
Correlation coefficient $(\mathrm{r})$ & 0.9998 & 0.9999 \\
\hline
\end{tabular}

The statistical parameters given in the regression equation were calculated from the calibration graphs. The high values of the regression coefficients and low values of $y$-intercepts of the regression equations, proved the linearity of the calibration curves. 


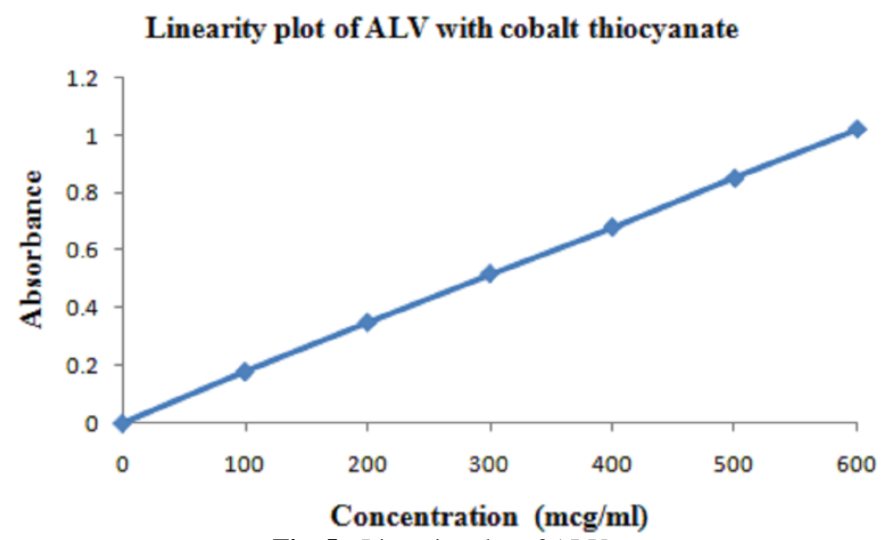

Fig. 5: Linearity plot of ALV.

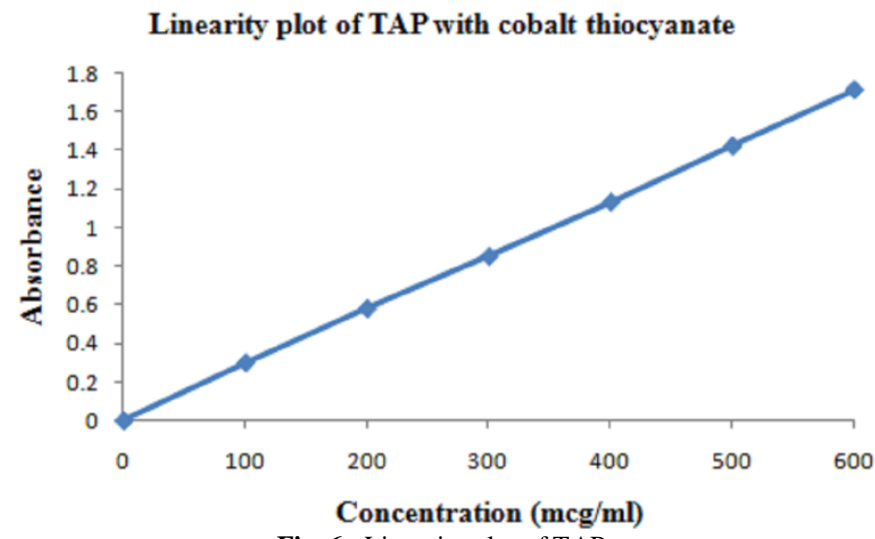

Fig. 6: Linearity plot of TAP.

Precision

The precision of the proposed methods was assessed by determining the relative standard deviation (RSD) of six replicate analyses at $80 \%$ level of ALV/TAP in linearity range. The low \% RSD of the intraday and interday repeatability studies corroborates precision of the method. Table 4 represents the results of precision studies.

Table 4: Results of precision studies.

\begin{tabular}{lllll}
\hline Parameter & \multicolumn{2}{c}{$\mathbf{A L V}$} & \multicolumn{2}{c}{ TAP } \\
\cline { 2 - 5 } & \multicolumn{1}{c}{$\begin{array}{c}\text { Intra day } \\
\mathbf{n = 6}\end{array}$} & $\begin{array}{c}\text { Inter day } \\
\mathbf{n = 6}\end{array}$ & $\begin{array}{c}\text { Intra day } \\
\mathbf{n = 6}\end{array}$ & $\begin{array}{c}\text { Inter day } \\
\mathbf{n = 6}\end{array}$ \\
\hline Conc & \multicolumn{2}{c}{$400 \mu \mathrm{g} / \mathrm{ml}$} & \multicolumn{4}{c}{$400 \mu \mathrm{g} / \mathrm{ml}$} \\
Mean abs & 0.68 & 0.675 & 1.13 & 1.131 \\
SD & 0.006325 & 0.010488 & 0.006325 & 0.007528 \\
\% RSD & 0.93 & 1.55 & 0.55 & 0.66 \\
\hline
\end{tabular}

Robustness

Robustness was checked by narrow alteration of the optimized parameters and the \% RSD was $0.4 \pm 0.12$ and $0.6 \pm 0.04$ for ALV and TAP, respectively which was satisfactory.

\section{Limit of detection $(L O D)$ and limit of quantification $(L O Q)$}

LOD and LOQ were determined by analysing progressively lower concentrations of standard solution using optimized conditions and the results were presented in Table 3.
Accuracy

The validity and accuracy of the proposed methods were further assessed by recovery studies using the standard addition technique. For this purpose, a known amount of pure drug at three different levels was spiked to the fixed and known quantity of pre analysed formulation samples and the nominal value of the drug was estimated by the proposed methods. The results given in Table 5 establish that the methods were reproducible by low SD and \%RSD. No interference was evidenced from the commonly encountered formulation excipients.

Table 5: Results of accuracy studies of ALV and TAP by proposed methods

\begin{tabular}{lllccc}
\hline Drug & $\begin{array}{c}\text { Drug in } \\
\text { formulation } \\
(\boldsymbol{\mu g})\end{array}$ & $\begin{array}{c}\text { Std added } \\
(\boldsymbol{\mu g})\end{array}$ & $\begin{array}{c}\text { Amt } \\
\text { Found } \\
(\boldsymbol{\mu g})\end{array}$ & $\begin{array}{c}\text { \% Recover } \\
\text { ed }\end{array}$ & $\begin{array}{c}\boldsymbol{\%} \mathbf{R S D} \\
\mathbf{N = 3}\end{array}$ \\
\hline \multirow{3}{*}{ AL } & 400 & 200 & 598.42 & 99.73 & 0.135 \\
V & 400 & 400 & 797.80 & 99.72 & 0.066 \\
\hline \multirow{3}{*}{ TAP } & 400 & 600 & 997.38 & 99.73 & 0.093 \\
\hline & 400 & 200 & 597.52 & 99.58 & 0.112 \\
& 400 & 400 & 797.03 & 99.62 & 0.145 \\
\end{tabular}

\section{Application of the proposed methods to formulations}

To evaluate the proposed methods, they were applied to the determination of ALV/TAP in commercial formulations. The recoveries are close to $100 \%$, indicating that there is no serious interference in samples. The good agreement between these results and known values indicate the successful applicability of the proposed methods for the determination of ALV/TAP in formulations. The results are given in Table 6.

Table 6: Assay results of ALV/TAP.

\begin{tabular}{llll}
\hline Formulations & \multicolumn{1}{c}{$\begin{array}{c}\text { Label } \\
\text { claim(mg) }\end{array}$} & $\begin{array}{c}\text { Amount } \\
\text { found(mg) }\end{array}$ & $\begin{array}{c}\text { \% Recovery } \\
\mathbf{N = 3}\end{array}$ \\
\hline Spasverin (tablet) & 60 & 59.83 & 99.71 \\
Tapenta (tablet) & 100 & 99.93 & 99.93 \\
\hline
\end{tabular}

\section{CONCLUSION}

Two new, cost effective, simple and sensitive visible spectrophotometric methods, using cobalt thiocyanate were developed for the quantitation of ALV and TAP in bulk and in pharmaceutical formulations. The developed methods were also validated. From the statistical data, it was found that the proposed methods were accurate, precise and reproducible and can be successfully applied to the analysis of the same and could make a better alternative to the existing methods.

\section{REFERENCES}

British Pharmacopoeia. 2008. The British Pharmacopoeia Commission, London. 114

Singh DR, Nag K, Shetti AN, Krishnaveni N. Tapentadol hydrochloride: A novel analgesic. Saudi. J. Anaesth. 2013; 7:322-26.

Asha S, Deepa Ramani N and Nanda Kishore A. Method Development and Validation of Tapentadol Hydrochloride by RP-HPLC in pure and tablet dosage form. J. Chem. Pharm. Sci, 2012; 5:178-80. 
Babu K and Madhu Kathirvel S. Development and Validation of visible spectrophotometric method of Tapentadol Hydrochloride in bulk and Pharmaceutical dosage form. Res. J. Pharm. Dosage Forms. Tech. 2012; 4:328-31.

Deepti J and Pawan Kumar B. Determination of Tapentadol Hydrochloride in tablets by three new validated spectrophotometric methods. Pak. J. Anal. Environ. Chem. 2013; 14:38-43.

Indira Muzib Y, Ravi Kumar Reddy J, Chowdary KPR and Swathi E. Development and validation of RP-HPLC method for estimation of Tapentadol hydrochloride in bulk and tablet dosage forms. Int. J. Chem. Anal. Sci. 2013; 4:67-72.

Krishnamoorthy G, Gayathri N, Ismail AM, Senthamarai R and Shakila BS. Determination of Tapentadol hydrochloride in bulk and its solid dosage form by UV-spectrophotometry. Int. J. Pharm. Sci. Rev. Res. $2014 ; 25: 139-41$.

Noel AG, Avdhoot L, Ashutosh R, Santosh Joshi S, Vikas VV and Jayram AT. Validated LC-MS/MS method determination of alverine and one of its hydroxyl metabolites in human plasma along with its application to a bioequivalence study. J. Chromatogr. B. 2009; 877:19706.

Omkar D and Priti J. Development and validation of RP- HPLC, UV-spectrometric and spectrophotometric method for estimation of Tapentadol hydrochloride in bulk and in laboratory sample of tablet dosage form. J. Chem. Pharm. Res. 2012; 9:4134-40.

Rizwana I, Vanitha Prakash K, Krishna Mohan G, Samreen J and Fatima S. Validated colorimetric methods for the determination of tapentadol in bulk and its tablet dosage form. Pharm. Res. Lib. 2014; 2:310-14.

Suresh Babu B, Krishna Pavan K, Nataraj K and Ramakrishna N. Development and validation of UV-Visible spectrophotometric method for the determination of Tapentadol hydrochloride from tablet dosage form. Der Pharm. Let. 2013; 5:377-82.
Vijayalakshmi R, Poorna Chandra Rao M, Naveena VSH, Aishwarya M, Rajasekhar K and Dhanaraju MD. Colorimetric estimation of few pharmaceutical agents miglitol, carvedilol and alverine citrate in pure and tablet dosage forms using MBTH. Der Pharm. Chem. 2014; 6:2023.

Ghosh C, Jha V, Ahir R, Shah S, Shinde CP and Chakraborty BS. A rapid and most sensitive liquid chromatography/tandem mass spectrometry method for simultaneous determination of alverine and its major metabolite, parahydroxyalverine, in human plasma: application to a pharmacokinetic and bioequivalence study. Drug Test. Anal. 2010; 2:284 89.

Rahul CG, Ketan KN, Ashok MK, Mitesh R, Satish GP and Prafullakumar K. Liquid chromatography/tandem mass spectrometry for the simultaneous determination of Alverine and its metabolite, monohydroxy Alverine, in human plasma: Application to a pharmacokinetic study. E-J. Chem. 2011; 8:201-11.

Kumar M, Jerad Suresh A, Maheshkumar G and Niraimathi V. Forced degradation study of alverine citrate in acid by UV spectrophotometry method. Indo Amer. J. Pharm. Res. 2013; 3:9093-96.

\section{How to cite this article:}

Vijayalakshmi Rajendran, Naga Sri Ramya Yerrapothini, Sasi Kiran Guntamukkala, Keziya Sugandha, Dhanaraju Magharla Dasaratha. Method Development for Quantification of DonorAcceptor Complexes of Alverine Citrate and Tapentadol by Visible Spectrophotometry. J App Pharm Sci, 2015; 5 (08): 068-072. 